\title{
Environmental Flow for Sungai Johor Estuary
}

\author{
A.Kadir Adilah ${ }^{1, *}$, Yusop Zulkifli ${ }^{2}$, Z. Noor Zainura ${ }^{1}$, and Baharim N.Bakhiah ${ }^{3}$ \\ ${ }^{1}$ Faculty of Chemical and Energy Engineering, Universiti Teknologi Malaysia \\ ${ }^{2}$ Resource Sustainability Research Alliance, Universiti Teknologi Malaysia \\ ${ }^{3}$ School of Marine and Environmental Sciences, Universiti Malaysia Terengganu
}

\begin{abstract}
Sungai Johor estuary is a vital water body in the south of Johor and greatly affects the water quality in the Johor Straits. In the development of the hydrodynamic and water quality models for Sungai Johor estuary, the Environmental Fluid Dynamics Code (EFDC) model was selected. In this application, the EFDC hydrodynamic model was configured to simulate time varying surface elevation, velocity, salinity, and water temperature. The EFDC water quality model was configured to simulate dissolved oxygen (DO), dissolved organic carbon (DOC), chemical oxygen demand (COD), ammoniacal nitrogen $\left(\mathrm{NH}_{3}-\mathrm{N}\right)$, nitrate nitrogen $\left(\mathrm{NO}_{3}-\mathrm{N}\right)$, phosphate $\left(\mathrm{PO}_{4}\right)$, and Chlorophyll a. The hydrodynamic and water quality model calibration was performed utilizing a set of site specific data acquired in January 2008. The simulated water temperature, salinity and DO showed good and fairly good agreement with observations. The calculated correlation coefficients between computed and observed temperature and salinity were lower compared with the water level. Sensitivity analysis was performed on hydrodynamic and water quality models input parameters to quantify their impact on modeling results such as water surface elevation, salinity and dissolved oxygen concentration. It is anticipated and recommended that the development of this model be continued to synthesize additional field data into the modeling process.
\end{abstract}

\section{Introduction}

Estuaries face a host of common challenges. As more people flock to the shore, we are upsetting the natural balance of estuaries and treating their health. We endanger our estuaries by polluting the water and building on the lands surrounding them. These activities can contribute to unsafe drinking water and beach, closing of shellfish bed, harmful algal blooms, declines in fisheries, loss of habitat, fish kills, and a host of other human health and natural resource problems.

Sungai Johor has a total length of about $122.7 \mathrm{~km}$ with catchment area of $2636 \mathrm{~km} 2$. The river originates from Gunung Belumut and Bukit Gemuruh in the north and flows to the southeastern part of Johor and finally into the Straits of Johor. The major tributaries of Sungai Johor are Sungai Sayong, Sungai Linggiu, Sungai Semanggar, Sungai Lebam, Sungai Seluyut and Sungai Tiram. A great amount of pollutants from various sources, such

* Corresponding author: adilahabdulkadir@gmail.com 
as the sewerage network of the Johor Bahru, Pasir Gudang, Ulu Tiram, and Kota Tinggi cities, Industrial wastewaters from many industries in the surroundings, and agricultural wastewater containing fertilizers and pesticides are discharged into the Sungai Johor.

The primary purpose of the study is to apply hydrodynamic model and water quality model to Sungai Johor estuarine system using EFDC. The objectives of the study are listed as follows:

i. To calibrate the model utilizing historical data and field data collection.

ii. To do sensitivity analysis of input parameters of hydrodynamic and water quality model.

Depending on the characteristics of a system, one may choose an appropriate hydrodynamic model. For a large coastal system where both horizontal and vertical gradient are significant, one needs to apply a three dimensional hydrodynamic model. Therefore the Environmental Fluid Dynamic Code, EFDC [1], is selected for the model build up. An intensive field observation surveys is conducted by the UTM research group during January- June 2015. Field data are required to specify the initial conditions, boundary conditions, and forcing function distributions in time and space for the calibration, verification and application of a three-dimensional hydrodynamic and water quality model of the study area.

The river quality water in lestuaries, indicating multiple inputs of pollutants along the river systems [2]. As shown in Fig. 5 and 6, stations 3JH19 and 3JH20 are categorized as clean or Class II except in June 1997 and the year 2000, which have been categorized as polluted river and Moderate River, respectively. Station 3JH20 is located near Kota Tinggi bridge and station 3JH19 is approximately 7 kilometers upward from station 3JH20. Stations 3JH13 and 3JH15 are categorized as clean river or Class II. Station 3JH13 is located near Kampung Rantau Panjang, Kota Tinggi and station 3JH15 is located approximately 5 kilometers downward of station 3JH13.

\section{Results}

All model coefficients should be consistent between the calibration period and the verification period. The method used in determining the values for the model coefficients is essentially one of trial and error. An intensive survey conducted in January 14-30, 2008 was used as calibration data set. The order in which the hydrodynamic model is calibrated is performed to address issues such as bathymetry, friction, tidal volume, cross-sectional area, and heat budget before salinity is calibrated. Salinity is the predominant signal in the model to ensure that mass is being moved horizontally and vertically with the appropriate timing and direction.

During the calibration process, Bottom roughness values are adjusted until the predicted results reasonably matched the observed data. The model results were compared against observed data in the study period (January 14-30, 2008). The temporal profiles of observed and predicted tide level are compared in for the calibration period. As shown in Fig. 1, the predicted tide levels reasonably matched the observed data at two sampling stations: Teluk Sengat and Tanjung Surat. These figures indicate that the model reasonably simulated the tide range and phase at a number of locations throughout Sungai Johor estuary. The simulated water level showed a good and fairly good agreement with observations, indicated by the low values of root mean square as shown in Fig. 2 and 3 respectively. Bottom roughness is very sensitive to water surface elevation at upper Sungai Johor and insensitive to lower Sungai Johor. 


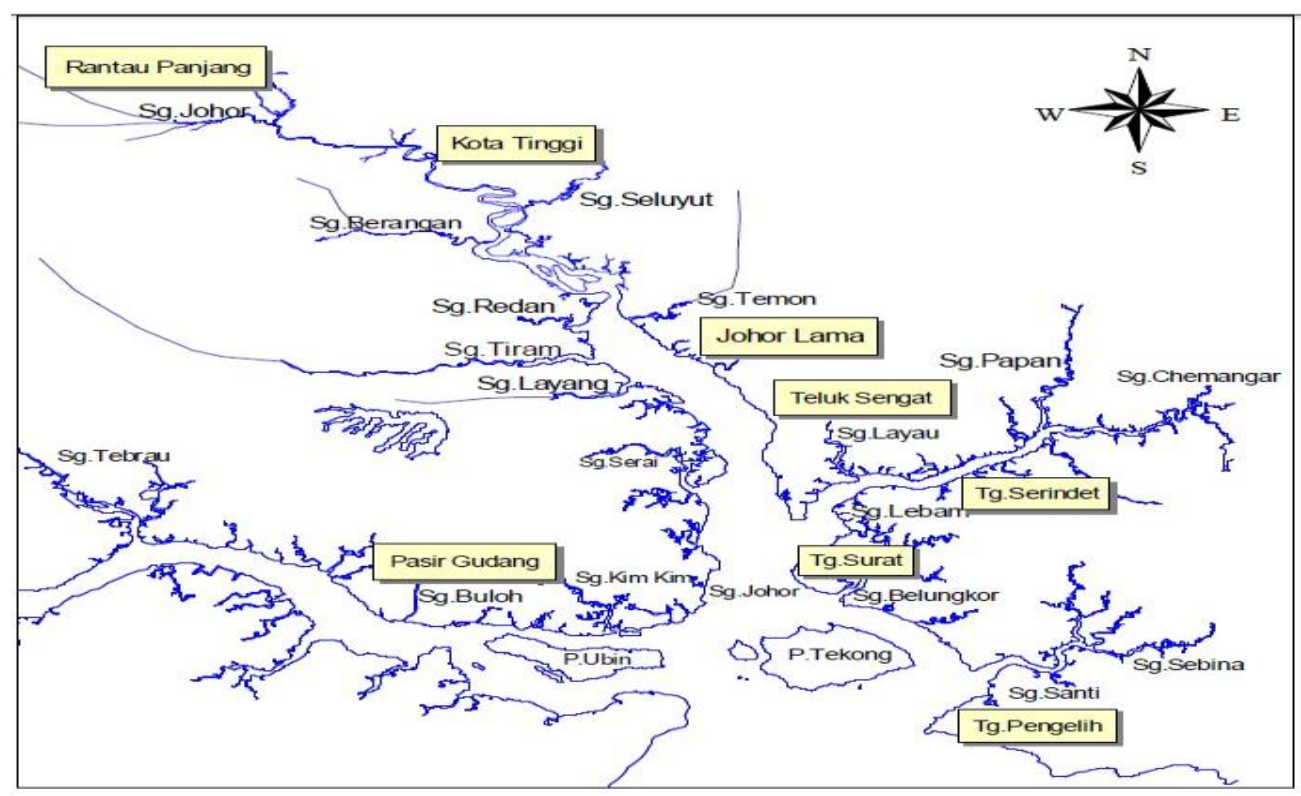

Fig. 1. Map of Sungai Johor study area.

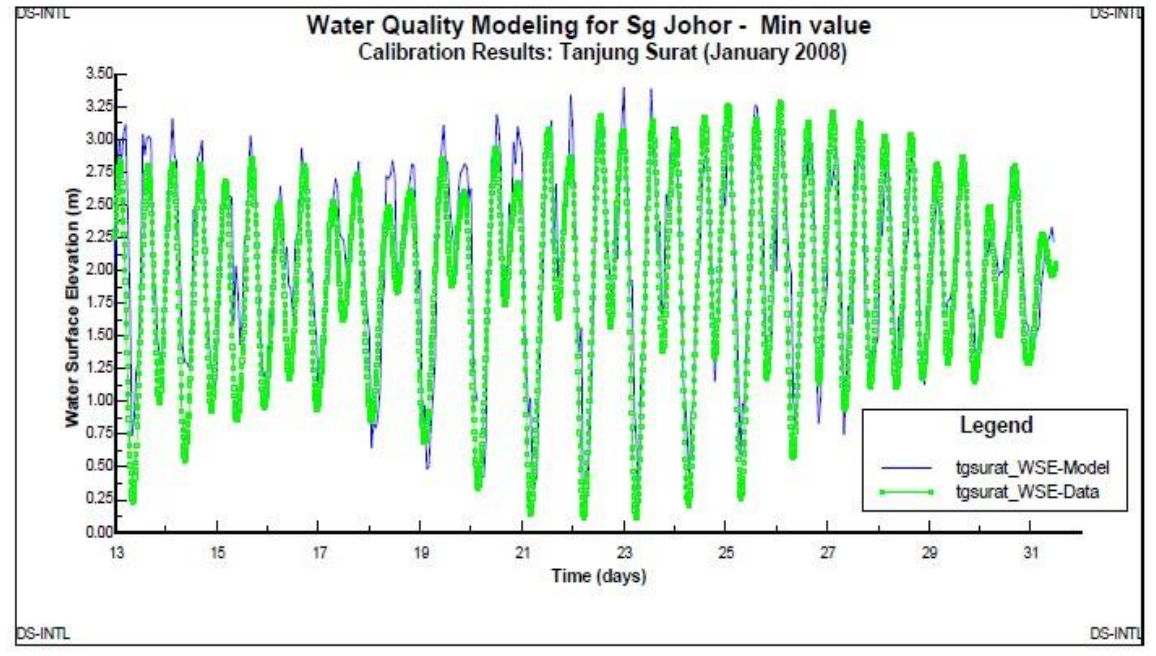

Fig. 2. Observed and simulated water surface elevations at Station Teluk Sengat. 


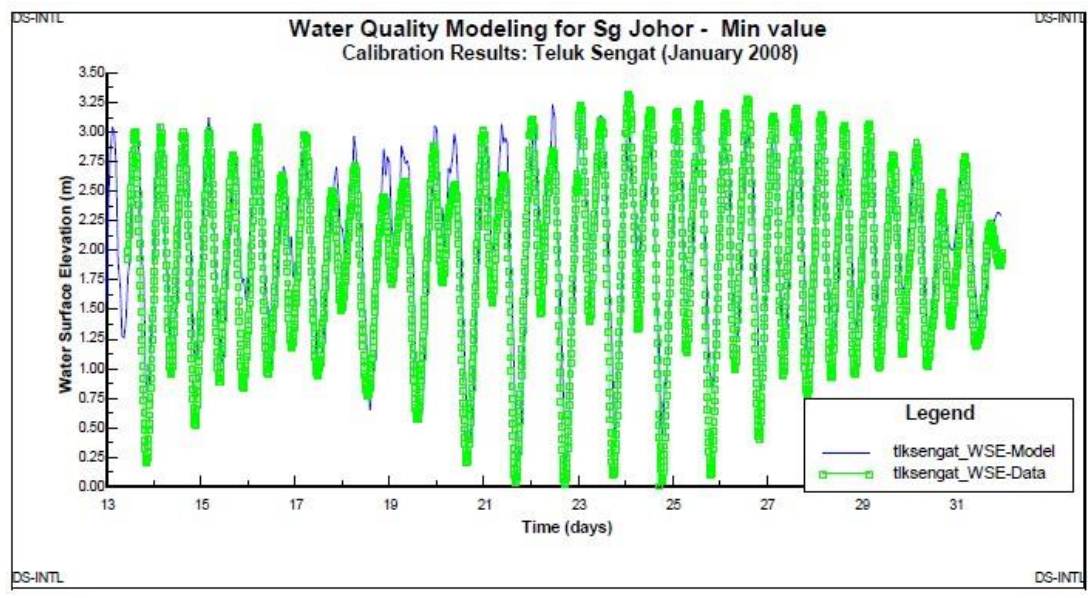

Fig. 3. Observed and simulated water surface elevations at Station Teluk Sengat.

\section{Conclusions}

The mechanisms that appear to be of significant include the absorption of phosphate to sediment particles and subsequent settling, transportation of sediment in response to high freshwater flow and the release of sediment phosphate. It was not because of the model but because of the quality and quantity of the field data used for the current calibration.

\section{References}

1. A. Elshafie, N. Ali, A.O. Karim, O. Jaafar, European Journal of Scientific research 28(3), 422-435 (2009)

2. R.B. Ambrose, Journal of Environmental Engineering 113(4), 703-721 (1987)

3. R.B. Ambrose and J.L. Martins, Technical Guidance Manual for Performing Waste Load Allocations, Book III: Estuaries, Part I, Estuaries and Waste Load Allocations, (U.S. Environmental Protection Agency, Washington, D.C., 1990)

4. R.B. Ambrose, T.A. Wool, J.L. Martin, Centre for Exposure and Assesment Modelling, (Athens, GA, 1993)

5. J.M. Beman, K.R. Arrigo, P.A. Matson, Nature 434, 211-214 (2005)

6. A. Blumberg and G.L. Mellor, Three dimensional coastal models, (Americn Geophysical union, Washington D.C., 1987) 